\title{
La imagen de la vida conventual durante los siglos XVI, XVII y XVIII
}

Claudia RuIz GARCÍA Universidad Nacional Autónoma de México

L'esprit monastique est le fléau des états

La Chalotais

Si se revisa la historia de la vida conventual en algunos países de Europa, en particular del ámbito meridional, descubrimos que dicha práctica nace desde los primeros siglos de la era cristiana. En un principio, persigue sobre todo apartar a las jóvenes de las tentaciones mundanas. Además el claustro es, después de la casa, un centro de enseñanza y de aprendizaje, el primero que se conoce en el mundo de la cristiandad. Sin embargo, poco a poco el rostro de esta institución se transforma, convirtiéndose en una vía para controlar y "restringir la salida de riqueza de la familia [y en] un refugio del superávit de hijas en los medios nobles y burgueses" (M. L. King, 1999: 281), ya que su ingreso exigía de una dote un tanto excesiva, aunque menor que la matrimonial. La razón de dicha exigencia residía en que, con ello, se aseguraba a los padres nobles la convivencia de sus hijas con jóvenes de su misma posición social, pues frente a tales condiciones de pago resultaba a veces muy difícil, para una buena parte de la burguesía incipiente, solventar dichas sumas. Con todo, debe reconocerse que a este último grupo no se le negaba el acceso al convento, pero sí se le restringían algunos privilegios. Se sabe que aquellas religiosas de cuna noble y que habían entregado una dote importante, contaban con un margen de libertad mucho más amplio y gozaban de una serie de prerrogativas, tales como tener una celda privada. En cambio, aquellas cuyo origen social era inferior, padecían más los estragos de las limitaciones y prohibiciones propias de la clausura, además de ser simples servidoras de las religiosas de gran linaje. Esta forma de encierro responde a una necesidad social que según Margaret L. King habría de modificar una práctica propia de la antigüedad romana que consistía en optar: "por 
criar sólo a dos hijas, a las cuales les proporcionaban una dote; a las otras las dejaban morir o las abandonaban. Las hijas abandonadas se convertían en esclavas o prostitutas o iban a parar a familias de un nivel social más bajo" (King, 1993: 112).

De esta forma, la aparición del convento cambió la suerte de muchas mujeres, pero al mismo tiempo supuso una serie de problemas de otro tipo. En primer lugar, no hay que perder de vista que sólo un porcentaje muy limitado se recluía por voluntad propia, con el afán de lograr una vida plena de santidad. El otro gran porcentaje ni siquiera podía cuestionar su entrada al claustro porque de antemano pesaba sobre estas jóvenes una razón de carácter económico, que no se podía ni siquiera objetar. Es este sector de la población conventual el que nos interesa observar más de cerca en las siguientes líneas.

Cuando se revisa la crisis de la Iglesia católica, de manera inmediata se hace patente la postura de varios reformadores de la Iglesia con respecto al encierro. Se sabe, por ejemplo, que Martín Lutero fue uno de los primeros en cuestionar los criterios de ingreso a los conventos así como su utilidad, definiéndolos más bien como cárceles para solteras.

Erasmo de Rotterdam, por su parte, no descansó hasta haber manifestado en varias ocasiones su aversión y horror por cualquier tipo de reclusión, ya fuera para hombres como para mujeres. Junto con su hermano, fue víctima de una ley civil y religiosa que castigaba a los hijos que nacían fuera del matrimonio y que además pesaba sobre ellos el hecho de que el padre fuera un miembro de la Iglesia. Así, se les negó el derecho a recibir una herencia que provenía de los bienes paternos y como Erasmo contaba con una gran capacidad intelectual para dedicarse al estudio, no le quedó más remedio que ingresar al monasterio sin poder nunca más frecuentar la escuela. En la gran mayoría de sus biografías se recogen episodios amargos de lo que fue su estancia monástica. Uno de los lugares que más marcó a Erasmo fue el Colegio de Montaigu en París, que recordó siempre como una prisión donde imperaban un régimen ascético que tocaba todos los límites de la crueldad y un sistema pedagógico fundado en castigos brutales y humillaciones sistemáticas, además de que allí sólo reinaba la inmundicia y la inmoralidad.

De esta forma, en dos de sus coloquios, "La virgen que odia el matrimonio" y "La virgen arrepentida", Erasmo revela parte de una experiencia personal durante su adolescencia, criticando las estrategias oscuras de los adultos para encerrar en monasterios y conventos a jóvenes que aún no pueden decidir si ese tipo de vida es realmente lo que les interesa. En el primero de ellos, dos jóvenes dialogan: Eubulio y Catalina. El jo- 
ven le expresa a Catalina su deseo de casarse con ella. Entonces ella le confiesa que desde su infancia decidió ingresar al convento para llegar a ser religiosa. Le explica que únicamente está esperando cumplir diecisiete años para hacer sus votos, tomar el velo y así permanecer virgen toda su vida. Eubulio y Catalina intercambian opiniones como las que se presentan a continuación:

EUBULE: c'est une chose magnifique que la virginité, si elle est sans tache, mais il n'est nullement indispensable que pour la conserver tu te voues à une communauté dont par la suite tu ne pourras être retirée. Il t'est possible de garder ta virginité auprès de tes parents.

CATHARINE: Oui, mais pas avec la même sécurité.

EUBULE: Mais si, à mon avis, avec plus de sécurité qu'auprès de ces moines épais, toujours ballonnés par la nourriture. Car ils ne sont pas châtrés, pour que tu ne l'ignores pas. On les appelle "Pères" et souvent ils font en sorte que ce nom leur convienne vraiment. Jadis nulle part les vierges ne vivaient plus sagement qu'auprès de leurs parents et elles n'avaient pas d'autre Père que l'évêque (Erasme, 1991: $684-685){ }^{1}$

El interlocutor de Catalina queda aún más sorprendido cuando ella le dice que ya eligió la orden a la que quiere pertenecer. Se trata de las "crisercianas", palabra inventada por Erasmo para aludir al apego por los bienes materiales de la gran mayoría de las congregaciones religiosas. Así, Eubulio, con conocimiento de causa, aprovecha para hacer resaltar las costumbres livianas de algunos padres y madres superioras que dirigen los conventos, calificándolos de ignorantes, golosos, viciosos y sáficas. No obstante, lo que más sobresale de este coloquio es la defensa encarnizada que Erasmo hace de la libertad humana. En un pasaje Eubulio señala:

Maintenant tu tends spontanément à te rendre de libre esclave. La clémence chrétienne a éliminé presque en entier l'esclavage des

${ }^{1}$ Trad. E. La virginidad es maravillosa si es inmaculada, pero, para conservarla, de ningún modo es necesario entregarte a una congregación de la que no puedas más tarde apartarte. Puedes conservar tu virginidad viviendo con tus padres.

C. Sí, pero no con tanta seguridad.

E. ¡Claro! Pienso que con mayor seguridad que al lado de esos monjes obesos, siempre inflados por la comida. Porque, para que lo sepas, no están castrados. Los llamamos "Padres" y hacen todo para que ese nombre les convenga. Antiguamente, no había virgen que no viviera más tranquila que junto a sus padres y no tenían otro Padre que el señor obispo. 
Anciens; seules des traces en subsistent encore dans de rares régions. Mais on a inventé sous le prétexte de religion un genre de servitude sans précédent selon lequel on vit actuellement dans la plupart des monastères [...] Et pour que ta servitude soit plus visible, on te fait quitter l'habit que t'ont donné tes parents pour en prendre un autre; et selon l'exemple antique de ceux qui jadis avaient acheté des esclaves, on change le nom que t'avait été donné au baptême... (Erasme, 1991: 988). ${ }^{2}$

Es importante recordar que la gran mayoría de los reformadores de la Iglesia católica se rebelan contra las condiciones y reglas de la reclusión por considerarlas vacías de sentido, además de tratarse de una falsa aplicación de los preceptos evangélicos. La obediencia ciega a ritos religiosos basados en horarios preestablecidos contra el deseo espontáneo de devoción y entrega íntima con Cristo es una de las múltiples aberraciones que el pensador holandés critica de la Iglesia romana, afirmando, en labios de Eubulio, que para llevar una vida religiosa basta simplemente tener bien presentes las enseñanzas de Cristo y ponerlas en práctica.

En el segundo coloquio "La virgen arrepentida", Eubulio visita a Catalina en el convento, cuando ya ha tomado el velo y la encuentra bañada en lágrimas. Ella le cuenta todos los sinsabores que ha sufrido en su nueva vida apartada del mundo y reconoce su falta: no haber tomado en cuenta las advertencias de Eubulio, lamentando además haber dilapidado la exagerada suma de dinero que le abrió la puerta del infierno. En el comentario de los dos coloquios mencionados, Erasmo opina lo siguiente:

Je maudis ceux qui attirent des adolescents ou des jeunes filles au monastère malgré leurs parents, en profitant de leur naïveté ou de leur superstition pour leur faire croire qu'il n'y a pas d'espoir de salut hors des monastères [...] Si un jour je suis obligé d'exprimer ce que je pense sur ce sujet, je peindrai ces faiseurs d'esclaves et la grandeur de leur forfait de telle sorte qu'il n'y aura personne pour nier que $\mathrm{j}$ 'ai eu quelque raison de donner cet avertissement, d'ailleurs

${ }^{2}$ Ahora de forma espontánea quieres dejar de ser libre para ser esclava. La clemencia cristiana eliminó casi por completo la esclavitud de la Antigüedad. Sólo en algunas regiones quedan ciertos vestigios de esto. Pero, bajo un falso pretexto religioso, se inventó una especie de servidumbre sin precedente, según la cual se vive actualmente en los monasterios [...] Y para que la servidumbre sea más visible te despojan de la ropa que te dieron tus padres para darte otra y, al igual que aquellos que antiguamente compraban esclavos, te cambian el nombre que se te había dado con el bautismo... 
en termes civils, pour ne pas donner aux méchants une occasion de faire mal (Erasme, 1991: 697). ${ }^{3}$

Se puede decir que de alguna forma Erasmo, como otros humanistas vinculados a la reforma de la Iglesia, abrieron la caja de Pandora, porque hicieron pública una realidad marcada por su carácter carceral, nunca antes vista así. Una prueba de ello se hace patente, en el momento de la Contrarreforma, cuando monjas así como parientes y familiares reaccionan con una serie de "protestas contra los intentos por parte eclesiástica de cortar los lazos que hasta entonces habían unido a las religosas con sus medios de origen" (Rosa, 1991: 246). Sin embargo, en pleno siglo XVII siguen multiplicándose en los conventos prácticas restrictivas y vigilancia absoluta de las reclusas. Mario Rosa apunta que, por ejemplo, en el monasterio de Lecce en 1629 se ordena hacer más estrechas las verjas de la reja del locutorio con el fin de que las monjas queden imposibilitadas a extender el brazo hacia el exterior y así poder tocar la mano o los dedos de alguien que se encuentre del otro lado. Además se mantiene la puerta principal atrancada con dos cerrojos, abriéndola únicamente en casos de extrema necesidad (Rosa, 1991: 248). La lista de prohibiciones se aplica también a los edificios contiguos al convento, ya que a éstos se les impide mantener las ventanas abiertas y se aplican castigos severos a las monjas que con disimulo miren hacia cualquier punto externo del ámbito claustral.

Ya en plena Contrarreforma, uno de los cambios visibles que se observa en los conventos consiste en modificar el valor y la importancia de los votos de la reclusa. La pobreza y la obediencia pierden cierto peso con respecto al voto de castidad, convirtiendo así a "los monasterios femeninos más que [en] lugares de santificación, [en] custodios de la virtud" (Rosa, 1991: 249). Esta preocupación se refleja en la vasta literatura ascética que se produce en ese momento, presentando casi siempre al convento como el único refugio donde el demonio se resiste a entrar para tentar a sus víctimas y hacerlas caer en el pecado de la carne. Además explica la razón por la cual se acrecientan las penitencias y mortificaciones corporales. Una forma muy común de autocastigo era cortarse o raparse

\footnotetext{
${ }^{3}$ Maldigo a aquellos que atraen adolescentes y jóvenes al monasterio, a pesar del deseo de sus padres, aprovechándose de su inocencia o de su superstición, al hacerles creer que no existe salvación eterna fuera de los monasterios [...] Si un día estuviera obligado a expresar lo que pienso al respecto, describiría a esos fabricantes de esclavos y la dimensión de su fechoria, de tal suerte que no habría nadie que pudiera negar que tengo razón en hacer tal advertencia, además lo haría en términos amables, para no darle oportunidad a los malvados de seguir haciendo más daño.
} 
los cabellos, ya que una cabeza rapada puede ser una prueba de entrega o esclavitud. Estas prácticas eran aceptadas y reconocidas como válidas por una fracción de las internas, como es el caso de Santa Teresa de Ávila y el de María de la Encarnación, entre muchas otras, que se deleitan con penitencias y flagelaciones extremas. También, son dignas de mencionarse Francesca Bussi, quien se quemó los genitales con cera, asegurándose así la pérdida del placer asociado a las relaciones sexuales o bien Angela de Foligno y Caterina Fieschi quienes bebían el agua que había servido para lavar la piel infectada de los leprosos (M. L. King, 1999: 162-163). En cambio, otro grupo - hay que reconocer que se trata de una minoría- prefirió no permanecer silencioso e indiferente frente a la nueva disciplina corporal y espiritual impuesta en los conventos. Entre estos casos aislados podría mencionarse, por ejemplo, a sor Arcangela Tarabotti, monja benedictina recluida en Santa Ana de Castello en Venecia. Fue víctima del encierro por una cuestión de nacimiento (no ser la primogénita de la familia) y cuenta con una sorprendente producción literaria donde denuncia este universo. En uno de sus textos más reveladores, $E l$ infierno monacal, expone la situación, en la gran mayoría trágica e injusta, de más de dos mil religiosas de su ciudad encerradas, sin vocación, por una simple razón de estado.

Debe reconocerse que el Concilio de Trento no se mostró sordo ante tales denuncias. El tema de las vocaciones religiosas fue ampliamente discutido en algunas de las sesiones y se tomó en cuenta en la parte relativa a las resoluciones. Sin embargo, todo quedó en el papel, porque en la práctica esta situación se mantuvo casi igual. Al revisar un texto de finales del siglo XVII —Vénus dans le cloître ou la Religieuse en chemiseprobablemente de 1682, observamos la misma queja en labios de una de las interlocutoras del diálogo, Angélique, quien afirma:

La politique a donc regardé toutes ses maisons [les couvents] comme des lieux communs où elle se pourrait décharger de ses superfluités. Elle s'en sert pour le soulagement des familles, que le grand nombre d'enfants rendraient pauvres et indigentes si elles n'avaient des endroits pour les retirer; et afin que leur retraite soit sans espérance de retour elle a inventé les vœux par lesquels elle prétend nous lier et nous attacher indissolublement à l'état qu'elle nous fait embrasser. Elle nous fait même renoncer aux droits que la nature nous a donnés, et nous sépare tellement du monde que nous n'en faisons plus une partie (Dubost, 1988: 325). ${ }^{4}$

${ }^{4}$ La política ha considerado todas sus casas [los conventos] como lugares comunes 
Hemos dicho anteriormente que una de las principales transformaciones que padecieron los conventos en el siglo XVII consistió en la preocupación por observar ante todo el voto de castidad, frente al de la pobreza y obediencia. Sorprende entonces el intercambio de opiniones de Angélique y Agnès a lo largo del texto. En la parte inicial del diálogo vemos a Angélique, una monja de veinte años, que intenta enseñar a Agnès, cuatro años menor que ella, los placeres lésbicos y la ciencia del libertinaje. De los primeros se encarga ella, mientras que para la otra disciplina, le confía a tres religiosos de diferentes órdenes y jerarquías la tarea de iniciar a su amiga en este tipo de ciencia. Más tarde las dos jóvenes se reencuentran para exponer las opiniones vinculadas con sus experiencias. De esta conversación se logra concluir que el texto, además de exponer una visión aguda y crítica de los conventos y del clero, ${ }^{5}$ insiste sobre todo en establecer los principios y la práctica de la filosofía del placer. Desde el comienzo Angélique advierte a Agnès que quiere compartir con ella sus hábitos secretos, dándole una muestra de lo que ella considera ser una verdadera religiosa. Su sabiduría no tiene nada que ver con ayunos, sacrificios y cilicios, al contrario, Angélique se subleva contra la idea de imaginar a los monjes y religiosas como seres desprovistos de cuerpo y deseos. A Agnès le dice que un cuerpo tan hermoso como el de ella no puede de ninguna forma asumirse como infame y sucio. A lo largo de este intercambio de experiencias y opiniones, Angélique insiste en demostrarle la necesidad de dejar que el cuerpo reaccione a cualquier impulso que provenga del exterior. De esta forma le dice:

donde podría deshacerse de lo que le sobra. Se sirve de éstas como alivio para las familias, que se volverían pobres e indigentes por el exceso de hijos, si no contaran con estos lugares para dejarlos y para que su encierro sea sin posibilidades de salir, inventó los votos por medio de los cuales pretende ligarnos y atarnos de manera indisoluble al estado que aparentemente nos deja elegir. Incluso nos obliga a renunciar a los derechos que la naturaleza nos ha dado, y nos separa tanto del mundo que ya no formamos parte de él.

${ }^{5}$ En un pasaje Agnès señala: "Je crois aussi que les pères et mères ne permettraient jamais l'entrée de nos maisons à leurs enfants s'ils en connaissaient le dérèglement", p. 331.

Creo que los padres y madres jamás permitirían a sus hijos el ingreso a nuestras casas si conocieran el desorden que existe.

Y Angélique en otro momento dirá: “Comme il n'y a point d'animal au monde plus luxurieux qu'un moine, il n'en est point aussi de plus malin et de plus vindicatif, lorsqu'on méprise son ardeur", p. 357.

No existe animal más lujurioso que un monje, ni tampoco más astuto y vengativo, cuando se desprecia su excitación. 
Pour moi, je trouve qu'il n'y a rien de plus doux et de plus délicieux quand on s'en acquitte comme il faut, et jamais je ne le mets en usage que je ne sois ravie en extase et que je ne ressente par tout mon corps un chatouillement extraordinaire et un certain je ne sais quoi que je ne te puis exprimer qu'en te disant que c'est un plaisir qui se répand universellement dans toutes les plus secrètes parties de moi-même, qui pénètre le plus profond de mon ccur, et que j'ai droit de le nommer: un abrégé de la souveraine volupté... (Dubost, 1988: 387). ${ }^{6}$

De esta forma podrían multiplicarse los pasajes donde las jóvenes reclusas intercambian opiniones de ese saber compartido y acrecentado por sus experiencias con los padres que las entrenan y además las inician a la lectura de libros prohibidos ("livres curieux") que llenan el vacío del tiempo conventual. Un tiempo que debe colmarse, no con rezos ni prácticas de devoción, considerados como ociosos, sino con la posibilidad de dar libre curso a los apetitos propios de la naturaleza humana, legitimando así el derecho a la voluptuosidad. Es éste el aspecto más revelador del texto que junto con otros dos escritos del siglo XVII - L'École des filles y L'Académie des dames ${ }^{7}$ - marcan toda una visión del derecho a la felicidad y a la libertad que definirá una de las máximas preocupaciones del pensamiento dieciochesco. En un momento del diálogo Angélique advierte:

6 "Para mí, no hay nada más dulce y delicioso como entregarse tal como se debe, y cada que lo hago siento el placer del éxtasis y siento por todo mi cuerpo un cosquilleo extraordinario y un no sé qué que únicamente puedo explicar diciéndote que es un placer que se expande por las partes más secretas de mi ser, penetra en lo más profundo de mi corazón y al que yo llamaria : un compendio de soberana voluptuosidad".

${ }^{7} \mathrm{~L}$ 'École des filles ou la philosophie des dames es considerada, dentro de la literatura francesa, como la primera obra erótica escrita en prosa. Muy probablemente fue redactada en la segunda mitad del siglo XVII y su autoría se le atribuyó a Michel Millot. Se cree que el editor fue Jean l'Ange, quien además de imprimir el libro se encargó de distribuirlo de manera clandestina. El texto gozó de un gran éxito y se tradujo al inglés muy poco tiempo después de su circulación en territorio francés. Se trata de la primera novela dialogada, que expone un aprendizaje de cierta filosofía del placer y de una pintura sistemática del libertinaje. Por su parte, L'Académie des dames se presenta como un manual de educación centrado en todo lo que una joven debe saber sobre sexo. Este texto aparece varias veces citado en otras obras eróticas del siglo XVIII, como una referencia obligada. Al igual que en L'École des filles, aquí dos primas intercambian un saber vinculado a su desarrollo personal libre de cualquier tipo de prejuicio. Una de ellas - Octavie - ha sido educada dentro de un esquema tradicional y su prima Tullie va a encargarse de mostrarle, en nombre de la razón, el camino para desprenderse de dicho molde que le ha impedido conocer la verdadera vía de un conocimiento libre de cualquier coacción. 
Je n'avais aucun penchant pour la Religion, je combattis vivement les raisons de ceux qui m'y portaient, et jamais je n'y serais entrée si un jésuite, qui pour lors gouvernait ce monastère, ne s'en était mêlé. Un intérêt de famille obligea ma mère [...] J'y résistai longtemps, parce que je ne prévoyais pas que le comte de La Roche, mon frère aîné, par le droit de noblesse et les coutumes du pays emporterait presque tout le bien de la maison et nous laisserait six, sans autre appui que celui qu'il nous aurait promis, qui, selon son humeur, devrait être peu de chose. Enfin il céda dix mille francs [...] auxquels quatre autres furent ajoutés, tellement que j'apportai quatorze mil livres pour ma dot en faisant profession dans ce couvent (Dubost, 1988: 332). ${ }^{8}$

Al leer estas líneas estamos forzosamente obligados a reconocer la clara correspondencia que existe entre este texto y La Religieuse de Diderot. Este último forma parte de un conjunto de obras del siglo XVIII, que persigue ante todo denunciar la crueldad del sistema y práctica social que hemos mencionado. Se le ha considerado, Grimm por ejemplo lo vio así, como la sátira más cruel y espantosa que nunca antes se haya hecho del claustro. De esta forma La Religieuse recoge y resume la queja de una gran cantidad de escritos - en particular de novelas - que abordan ese problema, recrudeciendo aún más los horrores de la reclusión y delineando el rostro del convento no tanto como un lugar de penitencia, sino más bien como una especie de prisión de trabajos forzados, demostrando además que su llegada e ingreso a él sólo se hacía por medio de un secuestro y violando, las más de las veces, la voluntad de las jóvenes. Dentro de este universo novelesco podríamos citar: Les Illustres françaises, Les amours du comte de Clare y La religieuse malgré elle de Brunet de Brou, y La paysanne parvenue de Mouhy, en donde una de las protagonistas cuenta su historia a la heroína principal, revelándole las causas de su encierro en un convento, uno de los pasajes de La Vie de Marianne de

\footnotetext{
${ }^{8}$ No tenía ninguna inclinación por la vida de religiosa. Combatí arduamente las razones de aquellos que me llevaban hacia ella y nunca hubiera ingresado aquí si no hubiera sido por un jesuita, que en ese entonces dirigía el convento y se inmiscuyó en el asunto. Por intereses familiares mi madre estuvo obligada a esto. Resistí durante mucho tiempo porque no había previsto que el conde de La Roche, mi hermano mayor, por derecho de nobleza y las costumbres del país, se llevaría todos los bienes de la familia y dejaría a seis de nosotros sin más apoyo que el que nos prometió que, según su estado de ánimo, sería poca cosa. Finalmente ofreció diez mil francos [...] a los cuales se le agregaron cuatro más, de modo que al profesar en este convento, aporté catorce mil libras como dote.
} 
Marivaux, la historia de Evandro et Fulvie. Histoire tragique, las Lettres turques y las Lettres d'une Péruvienne, entre otras tantas. En cada uno de estos textos el tono de la queja y de la rebelión es siempre serio y desgarrador. Estamos lejos de novelas como Vénus dans le cloître o Le Portier des Chartreux, donde la pintura de la vida conventual, a pesar de mostrar a veces una imagen poco amable, es asumida como una estancia privilegiada que de manera hipócrita permite, por ejemplo por medio de orgías conventuales, dar libre curso a las inclinaciones naturales.

La Religieuse, como muchos otros textos, se inspiró de una historia real que padeció Marguerite Delamarre y es muy probable que Diderot haya tenido muy presente la huella que el convento dejó en su hermana, Angélique, quien enloqueció dentro de sus paredes. En un principio, Diderot al concebir el esquema y el eje temático de la obra, estaba muy lejos de vislumbrar el alcance que tendría este escrito. Surgió más bien como una broma que Diderot y Grimm querían hacerle al devoto marqués de Croismare. Los dos sabían que este marqués había demostrado mucho interés en el caso de una religiosa que, en vano, había reclamado jurídicamente contra sus votos. Diderot le hizo creer que la monja había logrado escapar y desde su escondite le exponía su suerte y le solicitaba su ayuda para liberarse de los sufrimientos propios del encierro. Por un momento se pudo engañar al marqués haciéndole llegar unas cartas, supuestamente escritas por la hermana. Croismare le respondió y esto permitió que Diderot se lanzara a escribir las falsas memorias de la llamada "Suzanne Simonin". La broma se pudo sostener por algún tiempo, pero después, cuando Croismare descubrió la verdadera autoría del texto, todo el andamiaje cayó por su propio peso, dando lugar a la redacción de dichas memorias.

Queda claro que Diderot intentó, aparte de crear ese enmarañado juego detrás de la redacción de estas memorias, mostrar ante todo la aberración de cualquier forma de reclusión. Él mismo la había padecido, pues se sabe por fuentes epistolares que Diderot fue enviado a la prisión a petición de su padre. Se cuenta (Billy, 1951: XI) que el hijo lo había desobedecido, pues por órdenes paternas se le había prohibido su enlace matrimonial con una joven, Antoinette Champion, que no convenia a los intereses económicos de la familia. Antes de que el matrimonio se llevara a cabo el padre actuó con cierto rigor y consideró la prisión como el mejor medio para disuadirlo. Sin embargo, este castigo no tuvo el efecto que se esperaba, porque Diderot logró escapar de la cárcel por una ventana y, contraviniendo a los deseos de su padre, se casó más tarde con Mlle Champion en la clandestinidad. De esta forma entendemos por qué Claire 
Jacquier (1998: 95) afirma que, al abrir una ventana de la biografía del autor, descubrimos que "les mémoires de Suzanne ne sont pas l'authentique histoire d'une véritable religieuse, mais ils ne sont pas non plus une pure fiction, produit d'une invention spontanée". ${ }^{9}$ Es cierto que Diderot en varias de sus obras juega constantemente y mezcla o invierte la verdad con la ficción, lo real con lo irreal y, no obstante, en La Religieuse este juego queda circunscrito únicamente a la génesis del mismo. Si, por ejemplo en Jacques le fataliste, este mecanismo era evidente y recurrente, aquí la estrategia lúdica ha sido eliminada del mismo texto, dejándola sólo en su periferia. La novela se presenta como un texto auténtico en el que no cabe ninguna interrupción o conversación entre autor, narrador o lector, procedimiento muy gustado por este enciclopedista.

Dice Henri de Montherland que Diderot ha sido un autor poco leído y conocido a medias. Señala que un sector limitado de lectores comenzó a interesarse en él sólo a partir de la adaptación cinematográfica, a mediados de los años sesentas, de uno de sus textos, La Religieuse. Dicha adaptación desató una gran polémica, pues en el momento de su rodaje algunas comunidades religiosas solicitaron su prohibición. Posteriormente el gobierno se opuso a su proyección, a pesar de la opinión favorable que emitió la comisión de censura. Este veredicto levantó una campaña de protesta que incluso tuvo que discutirse en la Asamblea Nacional. La película se representó en el festival de Cannes y un año más tarde quedó libre de cualquier prohibición. Es preciso aclarar que desde 1826 la novela ya había sido censurada y posteriomente en 1884 el Dictionnaire d'Histoire et de Géographie de Bouillet la clasificó como licenciosa y frívola, además por mucho tiempo se leyó como un documento obsceno $\mathrm{y}$ anticlerical. Es cierto que la novela tal vez pudo haber herido la susceptibilidad de un púdico lector que probablemente se escandalizó frente a algunos pasajes, como por ejemplo las escenas contadas por Suzanne, cuando la madre superiora del convento de Saint-Eutrope la desviste el día de su llegada; la clase de clavecín durante la cual ésta desliza sus dedos sobre el pecho de Suzanne y se desmaya; la noche en la que ingresa a su celda de manera abrupta y le pide compartir su cama; el día que le solicita que la bese, situación que le provoca un orgasmo. Así dice la religiosa:

${ }^{9}$ Las memorias de Susana no son la auténtica historia de una verdadera religiosa, pero tampoco son una mera ficción producto de una invención espontánea. 
Elle m'invitait à lui baiser le front, les joues, les yeux, la bouche, et je lui obéissais: je ne crois pas qu'il y eût du mal à cela. Cependant son plaisir s'accroissait [...] La main, qu'elle avait posée sur mon genou se promenait sur tous mes vêtements, depuis l'extrémité de mes pieds jusqu'à ma ceinture, me pressant tantôt dans un endroit, tantôt en un autre; elle m'exhortait en bégayant, et d'une voix altérée et basse, à redoubler mes caresses: je les redoublais; enfin il vint un moment, je ne sais si ce fut de plaisir ou de peine, où elle devint pâle comme la mort; ses yeux se fermèrent, tout son corps s'étendit avec violence, ses lèvres se fermèrent d'abord, elles étaient humectées comme d'une mousse légère; puis sa bouche s'entrouvrit, et elle me parut mourir en poussant un grand soupir (Mauzi, 1972: 200). ${ }^{10}$

Además a estas escenas de cierto refinamiento perverso, deben sumarse los episodios de su estancia en el convento de Longchamps, donde la otra madre superiora la tortura, haciéndola soportar penitencias de extrema crueldad, que de alguna forma se anticipan a la violencia propia de los relatos sadianos, tales como obligarla a estar arrodillada durante todo el oficio religioso; a permanecer encerrada en su celda; a alimentarse de pan y agua; a ocuparse de las funciones más viles del convento; a no poder escribir y a caminar encima de pedazos de vidrio triturado, intimidándola $\mathrm{y}$ redoblando los castigos y mortificaciones a cada reacción de rebelión. Pero debemos reconocer que este tipo de escenas no están presentadas con la exageración característica de los textos de Sade. En cuanto a su carácter anticlerical vale decir que Suzanne Simonin en ningún momento imputa cuestiones propias del dogma cristiano. La queja de la monja está dirigida exclusivamente al efecto malsano de la reclusión. Veamos lo que en este ataque virulento Suzanne dice al respecto:

Voilà l'effet de la retraite. L'homme est né pour la société. Séparezle, isolez-le, ses idées se désuniront, son caractère se tournera, mille affections ridicules s'élèveront dans son cœur, des pensées extrava-

${ }^{10} \mathrm{Me}$ pidió que le besara la frente, las mejillas, los ojos, la boca, y yo obedecí: no creo que hubiera algo malo en esto. Sin embargo, su placer aumentaba [...] La mano que había puesto sobre mi rodilla se deslizaba sobre mi hábito, desde la punta de los pies hasta la cintura, apretándome en una parte y en otra. Tartamudeando en voz baja y perturbada, me suplicaba que volviera a acariciarla. Yo lo hice y de repente, no sé lo que pasó - si era placer o dolor-, pero se puso pálida como la muerte; sus ojos se cerraron, su cuerpo se estremeció con violencia; primero sus labios se cerraron, estaban humedecidos con una espuma ligera, y luego se abrieron, y me pareció, en el momento en que suspiraba, que iba morir. 
gantes germeront dans son esprit, comme les ronces dans une terre sauvage. Placez un homme dans une forêt, il y deviendra féroce; dans un cloître, où l'idée de nécessité se joint à celle de servitude, c'est pis encore; on sort d'une forêt; on ne sort plus d'un cloître; on est libre dans la forêt, on est esclave dans le cloître. Il faut peut-être plus de force d'âme encore pour résister à la solitude qu'à la misère; la misère avilit, la retraite déprave (Mauzi, 1972: 198). ${ }^{11}$

Éste es el eje rector del texto. A lo largo de las memorias se desliza una preocupación que Diderot considera como la prerrogativa inobjetable del hombre: el derecho a su libertad. En varios pasajes Suzanne insiste en demostrar que la privación a este derecho es el único motor de su rebelión. Al cumplir diecisiete años es incitada por su confesor a tomar el hábito. Ella rechaza esta propuesta, sin embargo, sus padres deciden enviarla al convento contra su voluntad. Esta reacción hace despertar una serie de sospechas en la joven y, poco a poco, logra imaginar la suerte que le espera: aceptar su reclusión a perpetuidad. De antemano está consciente de que no goza del derecho a dote, pues tiene dos hermanas mayores, además se pregunta si su padre ha tomado tal decisión para castigar a la madre que cometió adulterio. Así asume - aunque con cierta reserva- su futuro próximo: expiar dicha falta encerrada detrás de los muros de un claustro. Desde su primer contacto en tal recinto, se observará una fuerte resistencia de su parte. Todo lo que sucede allí suscita en la religiosa mil inquietudes. Lo que más teme es perder el control de su voluntad y dejarse gobernar como las otras reclusas. Por ello no es gratuito que en la parte inicial de las memorias, una de las situaciones que más le impresionan es haber visto caminar por uno de los pasillos a una monja enloquecida. Así, dice: "Je vis mon sort dans celui de cette infortunée et sur-le-champ il fut décidé dans mon cœur que je mourrais mille fois plutôt que de m'y exposer" (Mauzi, 1972: 54). ${ }^{12}$ Para ella, el convento, además de ser una prisión para su cuerpo, representa ante todo una fábrica cie

11 Éstos son los efectos de la reclusión. El hombre nació para vivir en sociedad: sepárelo, aíslelo y sus ideas se desarticularán, su carácter se invertirá, mil tristezas invadirán su corazón, ideas extravagantes germinarán en su mente, como los juncos en terreno silvestre. Ponga a un hombre en la selva y se convertirá en fiera. En un claustro es aún peor, pues a la idea de necesidad se suma la de la esclavitud. En una selva se puede ser libre, en el claustro se es esclavo. Quizá es preciso más ánimo para resistir a la soledad que a la miseria; la miseria envilece, el encierro deprava.

${ }^{12} \mathrm{Vi}$ mi suerte en la de aquella desdichada y de inmediato decidi con todo mi corazón que moriría mil veces, antes que exponerme a esto. 
locos y enajenados. Aquel que ingresa en estos recintos nunca más sale de ellos conservando la integridad de sus facultades mentales. Después de resistir en vano es obligada a tomar el velo:

On disposa de moi pendant toute cette matinée qui a été nulle dans ma vie, car je n'en ai jamais connu la durée; je ne sais ni ce que j'ai fait, ni ce que j'ai dit. On m'a sans doute interrogée, j'ai sans doute répondu; j'ai prononcé des vœux, mais je n'en ai nulle mémoire, et je me suis trouvée religieuse aussi innocemment que je fus faite chrétienne; je n'ai pas plus compris à toute la cérémonie de ma profession qu'à celle de mon baptême, avec cette différence que l'une confère la grâce et que l'autre la suppose (Mauzi, 1972: 86). ${ }^{13}$

Con todo, esa actitud de aparente pasividad va a transformarse poco a poco. Para cada prohibición habrá de su parte un cuestionamiento y una reiterada aclaración: no poder someterse a nada que lesione la integridad de su libertad, porque el sacrificio que se le ha impuesto ha sido contra su voluntad. Esta idea Suzanne intenta dejarla por escrito, motivo además para que más tarde le retiren el privilegio de tener tinta y papel en su celda. Por otra parte, ha declarado públicamente que siente que comete un terrible sacrilegio, vistiendo un hábito que desprecia profundamente. Para resistir contra todo lo que ella considera absurdo y arbitrario, se coloca del lado de la ley civil y religiosa. Aprende de memoria las reglas de las constituciones que rigen al convento y cada vez que se le ordena hacer algo que no esté estipulado en el documento, ella se defiende diciendo que no puede contravenir a lo marcado por la ley. De esta forma utiliza el argumento del respeto irrestricto a las reglas para proteger la integridad de su mente y de su cuerpo. Cuando es recluida en el convento de Saint-Eutrope se escuda en la ley para protegerse de los hábitos extraños y los deseos desenfrenados de la madre superiora. En un pasaje de las memorias cuenta que la madre entra a su celda por la noche, apaga la vela y se precipita a su cama. Comienza a abrazarla y le pide desesperadamente que calme su alma y tenga piedad de ella. Suzanne asustada

${ }^{13}$ Dispusieron de mí durante toda esa mañana, que además no vi pasar, porque nunca me di cuenta de lo que duró. No sé lo que hice ni lo que dije. Tal vez me interrogaron y seguramente respondi. Pronuncié mis votos, pero ya no recuerdo nada, y me convertí en religiosa de manera tan inocente como cuando me hicieron cristiana. No entendí lo que pasó durante la ceremonia en la que profesé, al igual que cuando me bautizaron, con la única diferencia de que con una se me concedió la gracia y con la otra se supuso ésta. 
decide levantarse de la cama. Entonces la madre superiora le suplica que permanezca con ella a su lado ya que sólo de esa forma logrará frenar su excitación y así tranquilizarse. Entonces la interna reacciona, diciéndole:

- Chère mère, lui dis-je, cela est défendu. Que dirait-on si on le savait? J'ai vu mettre en pénitence des religieuses pour des choses moins graves [...] le directeur $m$ 'a demandé quelquefois si l'on ne m'avait jamais proposé de venir dormir à côté de moi, et il m'a sérieusement recommandé de ne le pas souffrir. Je lui ai même parlé des caresses que vous me faisiez (Mauzi, 1972: 216). ${ }^{14}$

Ante esta defensa la madre superiora reacciona, intentando convencerla:

C'est moi qui récompense ou qui punis; et quoi qu'en dise le directeur, je ne vois pas quel mal il y a à une amie, à recevoir à côté d'elle une amie que l'inquiétude a saisie [...] Suzanne, n'avez-vous jamais partagé le même lit chez vos parents avec une de vos sœurs?

-Non, jamais.

-Si l'occasion s'en était présentée, ne l'auriez-vous pas fait sans scrupule? Si votre sœur, alarmée et transie de froid, était venue vous demander place à côté de vous, l'auriez-vous refusée?

- Je crois que non.

-Et ne suis-je pas votre chère mère?

-Oui, vous l'êtes, mais cela est défendu.

- Chère amie, c'est moi qui le défends aux autres et qui vous le permets et vous le demande. Que je me réchauffe un moment, et je m'en irai. Donnez-moi votre main... (Mauzi, 1972: 216). ${ }^{15}$

${ }^{14}$ Querida madre, le dije, eso está prohibido. ¿Qué dirían si lo supieran? A otras religiosas se les imponen penitencias por cosas menos graves [...] el director me ha preguntado a veces si me han propuesto dormir a mi lado y me recomendó con severidad que no lo acepte. Incluso le conté que usted me acariciaba...

${ }^{15}$ Soy yo quien recompensa y castiga y, a pesar de lo que diga el director, no veo qué daño se le puede causar a aquella que reciba a su lado a una amiga presa de inquietud [...] Susana, ¿nunca compartió en casa de sus padres la misma cama con alguna de sus hermanas?

-No, jamás.

-Si la oportunidad se le hubiera presentado, ¿no lo hubiera hecho sin escrúpulos? Si su hermana, inquieta y con frío, hubiera venido a pedirle que le permitiera acostarse a su lado ¿la hubiera rechazado?

- Creo que no.

-Acaso ¿no soy su madre querida? 
A lo largo de las memorias, estas muestras de resistencia permiten observar cómo poco a poco Suzanne cree reconquistar un derecho pisoteado por la familia y la Iglesia, ya que desde la temprana adolescencia se le privó de su capacidad para elegir y decidir el tipo de vida que deseaba. Sin embargo, una vez que logra huir del convento, con la ayuda de un monje benedictino, descubre que fuera de éste tampoco goza de dicha prerrogativa. Primero, padece los acosos del monje que la auxilió para evadirse, después, los horrores del hospital, pues al saltar los muros del claustro se ha hecho daño y, finalmente, los maltratos de una lavandera, con quien trabaja. Además, la huella que la reclusión ha dejado en su persona son visibles. Suzanne de manera inconsciente repite una serie de hábitos y costumbres del encierro. Los esfuerzos para liberarse de ese estigma son vanos. Incluso por su mente cruzan ideas propias de la locura, pues fuera de sus muros, añora la protección que éstos le daban, de tal forma que prefiere regresar al convento o terminar su vida arrojándose a un pozo, si no recibe el apoyo del marqués de Croismare.

Así queda claro que el convento, como ya lo había apuntado Erasmo de Rotterdam, sólo engendra monstruos, diablos y esclavos. Cualquier forma de encierro ya sea el monasterio, el asilo o la prisión, recintos que persiguen asistir a un grupo marginal de la sociedad que no tiene espacio en ellos, en lugar de corregir y enderezar su cuerpo y espíritu por medio de privaciones y castigos, los deforma. Es por esto que Diderot va a insistir en remplazar la educación monástica por una educación de Estado, obligatoria y laica capaz de formar jóvenes libres que sepan dar curso a los deseos e inclinaciones propias de la naturaleza humana, sin ningún sentimiento de culpa. Saint-Lambert, por su parte, intentará aplicar un Catéchisme universel (Hazard, 1963: 171) para uso de adolescentes de doce a trece años, donde se les enseñe la nueva esencia de los principios morales del siglo XVIII, a saber: la búsqueda perpetua del placer ilimitado y la huida y resistencia constante del dolor y la culpa, preocupaciones ampliamente ignoradas, censuradas o lesionadas dentro de esos espacios sin escapatoria. Llegamos así al terreno de la educación fuera del convento. Al respecto hay una vasta literatura que va desde Gargantúa o Pantagruel, pasando por L'École des filles, y textos tales como L'éducation de Laure de Mirabeau, Thérèse philosophe ou La philosophie dans le Boudoir del marqués de Sade que nos obligarían a revisar otros proble-

-Sí lo es, pero eso está prohibido.

-Querida amiga, soy yo quien lo prohíbe a las otras y quien lo permite y pide. Sólo me reconforto un momento y luego me voy de aquí. Déme su mano... 
mas que, aunque se desprenden del tema referido en estas líneas, podrían ser tratados en otro apartado.

\section{Obras citadas}

BILly, André, ed. 1951. Denis Diderot, La Religieuse. París: Gallimard. DuBost, Jean-Pierre, ed. 1988. Vénus dans le cloître ou la Religieuse en chemise, en Oeuvres érotiques du XVIIe siècle, t. 7. París: Fayard.

ÉRASME, Jacques Chormarat, ed. 1991. CEuvres choisies. París: Librairie Générale Française.

HAZARD, Paul. 1963. La pensée européenne au XVIIIe siècle. París: Arthème Fayard.

JACQUIER, Claire. 1998. L'erreur des désirs. Romans sensibles au XVIIIe siècle. Dijon: Payot Lausanne.

KING, Margaret L. 1993. Mujeres renacentistas. La búsqueda de un espacio. Madrid: Alianza Editorial.

. 1999. "La mujer en el Renacimiento". El hombre del Renacimiento. Madrid: Alianza Editorial.

MAUZI, Robert, ed. 1972. Denis DIDEROT, La Religieuse. París: Gallimard.

Montherland, Henry de, ed. 1972. La Religieuse. París: Librairie Générale Française.

RosA, Mario. 1991. "La religiosa". El hombre barroco. Madrid: Alianza Editorial. 